\title{
Vermicompost and Azotobacter as an ecological pathway to decrease chemical fertilizers in the maize, Zea mays
}

\author{
Ali Shirkhani ${ }^{1}$ and Safar Nasrolahzadeh ${ }^{2}$ \\ ${ }^{1}$ Agricultural And Natural Resources Research And Education Centre, Kermanshah, Iran \\ ${ }^{2}$ Department of Eco-physiology, Faculty of Agriculture, University of Tabriz, Tabriz, Iran
}

\begin{abstract}
Iran is a major importer of maize in the world. Maize is one of the most important crops in the western Iran. Maize production in this region has two major problems: water shortage and low percentage of organic matter in soil. In this research, effects of vermicompost and Azotobacter as a boifertilizers and chemical fertilizers levels on yield and Some traits of leaves of Maize under normal and deficit irrigation was investigated in two years (2014 and 2015). Results showed that grain yield, Leaf Area Index, leaf chlorophyll contents, the normalized difference vegetation index (NDVI) and Leaf relative water content (RWC) were decreased by deficient irrigation. Use of Azotobacter and vermicompost significantly increased these traits in normal and deficit irrigation. Results also showed that using 6 ton/ha of vermicompost and Azotobacter in soil, 50\% of the corn fertilizer supplied. The results showed that combined use of biofertilizers with chemical fertilizers increased the yield and other traits. Therefore the uses of biological fertilizers significantly reduce the consumption of chemical fertilizers and reduce the adverse environmental effects. So biofertilizers could be considered as a suitable substitute for chemical fertilizer in organic agricultural systems. On the other hand from this experiment, application of vermicompost in combination with chemical fertilizers showed better performance than only chemical fertilizers, even in 100\% recommendation based on soil test treatments. As a general conclusion these results suggest that integrating organic sources with 50\% of recommended NPK fertilizers are appropriate for sustainable crop production in normal and deficient irrigation.
\end{abstract}

KEY WORDS: MAIZE, VERMICOMPOST, AZOTOBACTER, CHEMICAL FERTILIZER, YIELD, LAI, NDVI, RWC

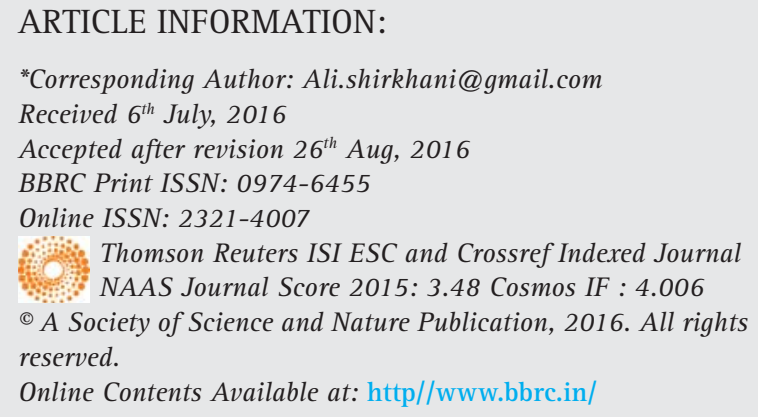




\section{INTRODUCTION}

Maize (Zea mays L.) is a major food, feed and industrial crop around the world. The crop provides food security and income to several million small holder farmers in Sub-Saharan Africa, Latin America and Asia. The area, production and productivity of maize have increased several-fold over the last five decades. In 2014, over 180 thousand hectares and 1.223 million tons of maize produced in Iran. However Iran was imported 6000 (1000 MT) maize grain. Maize is one of the most important crops in the western Iran and we have shortage in producing animal feeds, so, maize production is very important in Iran. The dearth of water is one of the important factors for maize production. The water shortage because of decreasing annual precipitation and the dry climate, and the other hand low fertility and low percentage of organic matter in soil are major problems in maize production in Iran. For this reason, overuse of chemical fertilizers in Iran is rising, leading to environmental pollution and soil degradation.

Soil water deficit reduces yield of maize (Zea mays L.) and other grain crops by three main mechanisms. First, whole canopy absorption of incident PAR may be reduced, either by drought induced limitation of leaf area expansion, by temporary leaf wilting or rolling during periods of severe stress, or by early leaf senescence. Second, drought stress reduces the efficiency with which absorbed PAR is used by the crop to produce new dry matter. Third, drought stress may limit grain yield of maize by reducing the harvest index (Earl and Davis, 2003 and Paroda and et al., 2014).

As heavy feeder of nutrients, maize productivity is largely dependent on nutrient management. Therefore, it needs fertile soil to express its yield potential. Farmers use chemical fertilizers to increase production to meet their needs, but the excessive use of fertilizers leads to contamination of soil and groundwater and reduce soil fertility. Moreover, Heavy agricultural reliance on synthetic-chemical fertilizers and pesticides is having serious impacts on public health and the environment. It killed the beneficial soil organisms \& destroyed their natural fertility, impaired the power of 'biological resistance' in crops making them more susceptible to pests \& diseases Runoff of soil and nitrogen fertilizer from corn-belt corn production has contributed to the anaerobic "dead zone" in the Gulf of Mexico.

The U.S. National Academy of Sciences (2003) reports that excessive fertilizer use costs $\$ 2.5$ billion from wasted fertilizer inputs. Hence, there is a need to search for alternative strategies to improve soil health without causing damage to environment as well as soil. Therefore, biofertilizers are gaining importance as they are ecofriendly, non hazardous and nontoxic products (Sharma et al., 2007, Adhikary, 2012).
The new approaches to the use of organic amendments in farming have proven to be effective means of improving soil structure, enhancing soil fertility and increasing crop yields. Vermicompost is an important type of non chemical fertilizers. Bio-fertilize is a densely populated preservative of one or more types of useful terricolous microorganism, their metabolic phenomenon are used to provide the nutrients needed by plants, control soil-borne diseases and maintain the stability of soil structure. Vermicomposts are finely divided, peatlike materials with high porosity, aeration, drainage, water-holding capacity, and microbial activity. Natural humic acids (HA) of vermicompost can be an ecological alternative to increase tolerance of plants to drought, precisely because they have been shown to stimulate protein synthesis in various plant organs and enzyme synthesis and/or activity (Muscolo et al., 2007).

In addition application of biocompost to consumable crop minimizes the use of chemical fertilizers improve the quality of soil (Tripathi et al., 2007). The addition of organic matter to the soil usually increases the water holding capacity of the soil. This is because the addition of organic matter increases the number of micropores and macropores in the soil either by "gluing" soil particles together or by creating favourable living conditions for soil organisms. Certain types of soil organic matter can hold up to 20 times their weight in water. The consequence of increased water infiltration combined with a higher organic matter content is increased soil storage of water (Reicosky, 2005 and Pandya et al. 2014).

Lately, a number of studies were carried out investigating the association of nitrogen-fixing microorganisms on the roots of non-leguminous plants, such as maize (Cvijanovic et al. 2007). Associative nitrogen fixing bacteria are present in all soils in unequal numbers. Their numbers depend on physical and chemical properties of the soil, the presence of oxygen, the presence and absence of $\mathrm{Ca}$ and $\mathrm{P}$, trace elements content, organic matter content, the presence of the antagonists and toxic chemicals, and can also be affected by different plant species. Associative nitrogen fixing bacteria are most abundant in plant rhizosphere and within root hairs zone (Malik et al. 2005).

The use of associative nitrogen-fixing bacteria (Azotobacter, Azospirillum, Derxia etc.) in the production of wheat, corn, sugar beet, sunflower and some vegetable crops, show that depending on the strain there is a possibility of replacing up to $60 \mathrm{~kg} \mathrm{~N}$ ha-1, and possibly even up to $150 \mathrm{~kg} \mathrm{~N}$ ha-1 of mineral fertilizer. As heavy feeder of nutrients, maize productivity is largely dependent on nutrient management. Therefore, it needs fertile soil to express its yield potential. Ideal soils are rarely found in nature. 
Organic manures not only supply the plant nutrients (Duhan and Singh, 2002). To alleviate the problem, INM is an option as it utilizes available organic and inorganic nutrients to build ecologically sound and economically viable farming system. Research has suggested that integrated nutrient management strategies involving chemical fertilizers and bio-fertilizers enhance the sustainability of crop production. Integrated plant nutrient managet (INM) is the combined use of mineral fertilizers with organic resources such as cattle manures, crop residues, urban/rural wastes, composts, green manures and biofertilizers (Kemal and Abera, 2015).

Integrated nutrient management (INM) is a judicious application of fertilizers or manures from different sources to a field in order to maintain the environmental sustainability. Saini et al., (2004), reported that using of 50 percent of chemical fertilizers and farm yard manure with inoculation of seeds by Rhizobium bacteria and phosphor solubilizing bacteria, increased grain yield and biomass of sorghum and chick pea. According to Akbari et al., (2009), combination of bio and chemical fertilizers increased grain yield, plant height, biological yield and harvest index of sunflower.

Also it has ben shown that application of 50\% N through chemical fertilizer $+25 \%$ through biocompost $+25 \% \mathrm{~N}$ through vermicompost significantly improved growth in terms of plant height, dry matter accumulation per plant and LAI over the treatment 100\% N through chemical fertilizer. Moreover, the use of bio stimulators in condition of environmental stress can decrease effects of stress and enhance soil water holding capacity, root growth and yield (Li and Ni, 1996 and Santosh and et al. 2013).

Furthermore, the concept of leaf area index was first introduced by Watson (1947) and defined as the ratio of leaf area to a given unit of land area (Jonckheere et al., 2004). Leaf area index is the component of crop growth analysis that accounts for the ability of the crop to capture light energy and is critical to understanding the function of many crop management practices. Leaf area index can have importance in many areas of agronomy and crop production through its influence on: light interception, crop growth weed control, cropweed competition, crop water use, and soil erosion.To measure LAI, scientists generally have cut a number of plants at the soil surface, separated leaves from the other plant parts, and measured the area of individual leaves to obtain the average leaf area per plant. The product of leaf area per plant and the plant population gives the LAI. Alternatively, LAI could be measured non-destructively with this procedure if area of individual leaves was determined by some combination of leaf length and width measurements.

The SunScan canopy analysis system (Delta-T Devices, Cambridge, UK) was designed to measure the light levels of photosynthetically active radiation (PAR), the interception of solar radiation and make estimates of LAI in plant canopies. SunScan probe estimates LAI indirectly from measurements of radiation above and below the canopy, based on a theoretical relationship between leaf area and canopy transmittance. Its optical sensor is the light sensitive "wand" of one meter long, containing 64 photodiodes equally spaced along its length (Potter et al., 1996). The SunScan canopy analysis system (Delta-T Devices, Cambridge, UK), rely on the strong dependency between canopy structure and gap fraction or size distribution of the canopy (Jonckheere et al., 2004).

The chlorophyll meter (or SPAD meter) is a simple, portable diagnostic tool that measures the greenness or the relative chlorophyll concentration of leaves. Compared with the traditional destructive methods, this equipment might provide a substantial saving in time, space and resources. The Minolta Soil Plant Analysis Development (SPAD-502) chlorophyll meter is one tool that enables researchers to determine chlorophyll content by measuring leaf greenness (Peterson et al., 1993). The SPAD uses a silicon photodiode to derive the ratio of transmittance through the leaf tissue at $650 \mathrm{~nm}$ compared with transmittance at $940 \mathrm{~nm}$, and a value is given based on that ratio. SPAD measures relative chlorophyll content in plant leaves. Because chlorophyll content is closely related to N supply (Pandey et al., 2000), SPAD is also used to diagnose corn $\mathrm{N}$ status and predict corn grain yield potential (Vetsch and Randall, 2004).

Janos (2010) reported a close correlation between N fertilization and SPAD readings. Increasing $\mathrm{N}$ application increased $\mathrm{N}$ content and chlorophyll content in corn (Rambo et al., 2010). Factors affecting SPAD values include radiation differences between seasons, variety and species differences, plant and soil nutrient status (including $\mathrm{N}$ and other nutrients), and biotic and abiotic stresses (Peterson et al., 1993).

The normalized difference vegetation index (NDVI) is widely used at ground level and from low, high and satellite altitudes to measure vegetative greenness and canopy photosynthetic size. Optical sensors that measure the reflectance from the corn canopy and then attempt to use that information to manage the crop have been available for more than a decade now. GreenSeeker (TM Trimble) is one of the better known sensors.The Normalized Difference Vegetative Index (NDVI) is a commonly used measurement of crop health in agricultural applications. NDVI is calculated as:

NDVI = (NIR reflected - Red reflected) / (NIR reflected +Red reflected), where Red and NIR stand for the spectral reflectance measurements acquired in the red and near-infrared regions, respectively. Healthier crop canopy will absorb more red and reflect more near infrared light, and consequently has a higher NDVI value. 
Jones and Wechler (2007) has used a GreenSeeker sensor (NTech Industries, Inc.) to measure NDVI and there was strong correlation between NDVI and chlorophyll content per plant of spinach $\left(\mathrm{R}^{2}=0.91\right)$. The NDVI has been correlated to many variables such as crop nutrient deficiency, final yield in small grains, and long-term water stress (Govaerts and Verhulst, 2010). NDVI was found to be closely correlated with the Leaf Area Index (Leon et al., 2003).This present research work was therefore conducted to assess the potential of the recommended dose of inorganic fertilizers and its 50\% amount alone and in combination with different doses of vermicompost and Azotoabcter inoculum as biofertilizer in order to explore the possibility of reducing the use of chemical fertilizersin maize under drought stress and normal condition.

\section{MATERIAL AND METHODS}

Field experiments were conducted for two years (2014 2015) at the agricultural research farm, Agricultural and Natural Resources Research Centre in Kermanshah, Iran. This farm is located at $34.08 \mathrm{~N}, 46.26 \mathrm{E}, 1345 \mathrm{~m}$ altitude, silty clay soil, $\mathrm{pH}=7.5-8,450 \mathrm{~mm}$ precipitation Mediterranean climate. In this research, effects of vermicompost and Azotobacter as a boi- fertilizers and chemical fertilizers on yield and yield components of Maize under normal and deficit irrigation was investigated in two sites. Sites included normal irrigation and deficient irrigation (65\% optimum water requirement) and each site was conducted as the factorial split plot in a randomized complete block design with three replications and three factors. Treatments included Azotobacter in the main plots (non-inoculation and inoculation), vermicompost (consuming 0,2 , 4 and 6 ton/ha) and chemical fertilizers included N,P,K in tree levels (100\% recommendation based on soil test, 50\% recommendation and no fertilizer) in the sub plots. The Maize cultivar used was "KSC 704" (a grain Maize cultivar that is commonly planted in the region).

Before planting $7 \mathrm{~g}$ inoculation with $1 \mathrm{~g}$ had 107 active and live bacteria, were used inoculating seeds. Seeds which must mix with Azotobacter soaked with sugar water with concentration $2 \%$ and with ratio $2 \mathrm{~kg}$ inoculation $100 \mathrm{~kg}$ seeds. Plot dimensions using in this study will be $7 \mathrm{~m}$ long by $3 \mathrm{~m}$ wide, each plot will be consisted four rows spacing at $0.75 \mathrm{~m}$. Vermicompost used in this study has been produced by the activity of Eisenia foetida worm produced from cattle manure. Phosphorus and potassium fertilizers were mixed by soil before cultivation. A quarter of urea fertilizer at planting, one-fourth of 6 to 8 leaf stage, and the remaining fertilizer was applied prior to flowering, before planting all quantities of vermicompost was mixed with soil to a depth of $30 \mathrm{~cm}$. Maize is an irrigated crop in Iran; therefore, it is not dependent on the seasonal rainfall. Irrigations were carried out at 7 day intervals. Water treatments (deficit and adequate irrigation) were initiated during middle vegetative growth stage (around V6). Beginning on these dates, water was applied at weekly intervals based on the amount of evapotranspiration for the previous week as determined by the on-site weather station using a modified version of the Penman FA0 equation (0'Neill et al., 2004).

The adequate irrigation treatment received the amount of water required to fully replace the previous week evapotranspiration while the deficit treatment received $65 \%$ this amount. This was continued throughout the remainder of the growing season. Relative chlorophyll (SPAD) content was measured in corn leaves with Minolta SPAD-520 meter (Konica Minolta Sensing, Inc., Japan) at the V8 and R1 stages. At least ten SPAD meter readings were collected either in the upper most fully expanded corn leaves (V8 stage) or ear leaves ( $\mathrm{R} 1$ stage) from each plot and the average value was recorded. Leaf Relative water content (RWC) was calculated by using the following equation:

RWC $(\%)=[$ fresh weight- dry weight/ turgid weight - dry weight $] \times 100$

Where FW, TW and DW are fresh weight (g), turgid weight (g) and dry weight (g) respectively. For this purpose, a fully expanded young leaf (ear leaf) was selected from each treatment and replication at the mid-canopy position before irrigation in flowering stage (four plants). Ten leaf pieces ( $2 \mathrm{~cm}$ diameter) were cut from these leaves and weighed immediately to record fresh weight (FW). Turgid weight (TW) was determined by weighing the leaf segments after $24 \mathrm{~h}$ of immersion in distilled water in a sealed flask at room temperature. Dry weight (DW) was determined by weighing the leaf segments after $48 \mathrm{~h}$ at $70^{\circ} \mathrm{C}$ in oven (Efeoglu et al., 2009).

For measuring the Leaf area index, SunScan canopy analysis system (Delta-T Devices Ltd., UK) was used. The instrument is indirectly measuring leaf area index by measuring the ratio of transmitted radiation through canopy to incident radiation. Normalized difference vegetation index (NDVI) is an estimate of biomass and nitrogen content in many crops. The NDVI sensor used in this research was a GreenSeeker Hand Held Data collection and Mapping Unit (NTech Industries, Inc., Ukiah, Cal.), according to the methodology of Verhulst and Govaerts (2010). Each plot was harvested at maturity for yield. The Maize ears located $6 \mathrm{~m} 2$ from each plot were harvested by hand, then allowed drying at $80^{\circ} \mathrm{C}$ to a constant weight and then seed yield was obtained.

\section{RESULTS AND DISCUSSION}

The LAI was significantly influenced by deficient irrigation; Results showed that LAI was decreased from 3.7 to 
2.1 by deficient irrigation. Corn yield is strongly depended on LAI, LAD and leaves efficiency for absorption of solar radiation for photosynthesis process. For most plant species, the shortage of nitrogen or water causes a reduction in leaf area development, changes in leaf tissue composition, leaf cell structure and plant water content (Casa, 2003) and also in maize, drought reduces leaf area, leaf chlorophyll contents, photosynthesis and ultimately lowers the grain yield (Athar \&t Ashraf, 2005).

Stone et al. (2001) reported that water deficit reduces crop growth and morphological characteristics of maize plant. In corn, reproductive growth after the silking and flowering stages is the critical period for yield, and chlorophyll content and intact chloroplast structure are key factors for accumulation of dry matter and high yields (Yu et al., 2010).

Analysis of variance showed that Azotobacter increased LAI about 0.1 in all treatments. But this increase was not statistically significant. Moreove leaf area index increased with increasing levels of chemical fertilizers and vermicompost. The maximum LAI 4.5 was recorded in the plots where 6 ton/ha vermicompost and $100 \%$ chemical fertilizer were applied. But with no vermicompost and 100\% chemical fertilizer LAI was 4 and with use of 6 ton/ha vermicompost and Azotobacter and 50\% chemical fertilizer LAI also was 4 , this result showed that use of vermicompost and azotobacter that means a 50\% reduction in the consumption of chemical fertilizers. Whereas without chemical fertilizer and with use of 6 ton/ha vermicompost and Azotobacter, LAI was 3.6 and 1.9 in normal and Deficient Irrigation condition respectively (Table 1).
Using of different Levels of fertilizers had significant effect on leaf area index of corn (Rasheeed et al., 2003). Yadav et al (2002) revealed that application of incorporation chemical and biofertilizers increased the biological yield, grain yield and LAI of blond plantago (Plantago ovate). In other study, application of incorporation chemical and bio-fertilizers on corn crop increased plant height, LAI, dry matter production, leaf area duration (LAD) and leaf area ratio compared with sole chemical fertilizers (Eidi Zadeh et al., 2010).

Verma (2011) reported Organic source of nitrogen application also influenced the plant height, leaf area index, dry matter production/plan recorded significantly more with the addition of FYM followed by Azospirillum and control, respectively. Manyuchi et al., (2013) showed that applying of vermicompost enhance maize leaves production more than 3 leaves per plant.

The results of this study showed that deficient irrigation decreased leaf chlorophyll contents from 40.6 to 37.7.0n the other hand bio and chemical fertilizers had a significant effect on leaf chlorophyll contents (Table 2). Vermicompost and Azotobacter increased leaf chlorophyll contents and also chemical fertilizers. The maximum chlorophyll contents (46.6) were observed from 6 ton/ha vermicompost + inoculation with Azotobacter $+100 \%$ chemical fertilizer in normal irrigation but with use of 6 ton/ha vermicompost and Azotobacter and 50\% chemical fertilizer chlorophyll contents was 45.2 and no significant different was observed. Also without chemical fertilizer and with use of 6 ton/ha vermicompost and Azotobacter, This trait was 35.2 and 32.3 in normal and deficient irrigation condition respectively.

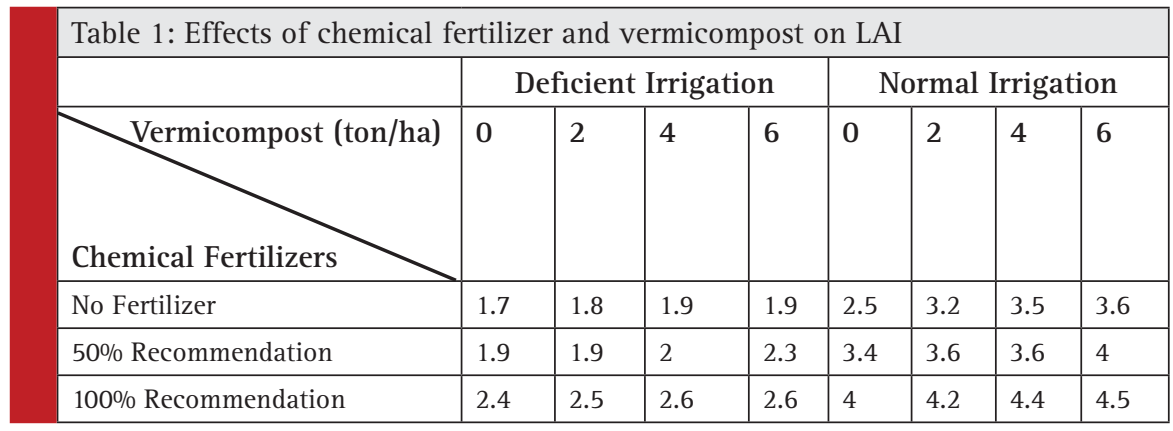

\begin{tabular}{|c|c|c|c|c|c|c|c|c|}
\hline & \multicolumn{4}{|c|}{ Deficient Irrigation } & \multicolumn{4}{|c|}{ Normal Irrigation } \\
\hline Vermicompost (ton/ha) & 0 & 2 & 4 & 6 & 0 & 2 & 4 & 6 \\
\hline No Fertilizer & 26.9 & 27.1 & 28.9 & 32.4 & 34.8 & 35.3 & 35.4 & 36.3 \\
\hline 50\% Recommendation & 35 & 37.1 & 38.2 & 44 & 37.6 & 38.3 & 40.3 & 44.7 \\
\hline 100\% Recommendation & 45.6 & 45.6 & 45.7 & 45.7 & 46.5 & 47 & 47 & 47 \\
\hline
\end{tabular}


Ciganda et al (2008) had similar results and reported that chlorophyll content is among the most important crop biophysical characteristics. Chlorophyll can be related to photosynthetic capacity, thus, productivity, developmental stage, and canopy stresses, also MunneBosch and Alegre (2000) reported the chlorophyll content was decreased with decreasing the irrigation water and this decrease was correlated with relative water content in leaves. Chlorophyll loss is a negative consequence of water stress. In addition, the negative effect of deficit irrigation was reflected in decreasing the chlorophyll content of rosemary leaves.

On the other hand, some authors found an opposite trend since chlorophyll increased by deficit irrigation. Khayatnezhad, (2011) reported that drought stress condition increased the leaf chlorophyll content in wheat genotypes. This is because the exact effect of deficit irrigation may vary according to the intensity of the water stress imposed (Cameron, 1999). These results are similar with the previous findings of Chamle et al. (2006).

Pandurang (2014) reported vermicompost increased Chlorophyll contents in maize. Casa (2003) reported that differences in leaf spectral reflectance, in particular those related to variations in the chlorophyll content of the leaves, have been used as an indirect means to assess nitrogen stress and Nitrogen availability typically affects leaf pigment concentration (e.g. chlorophyll) with a clear effect on leaf spectral reflectance. Studies show that when maize plants were subjected to PEG induced drought stress their chlorophyll a, b and total chlorophyll contents were significantly decreased due to leaf senescence acceleration (Efeoglu et al., 2009).

Inoculation with Azotobacter and use of vermicompost significantly influenced the NDVI. Two years mean revealed that maximum NDVI (0.78) was recorded with the application of recommended dose of chemical fertilizer plus 6 ton/ha vermicompost and Azotobacter inoculation and in normal irrigation, also with use of 6 ton/ ha vermicompost and Azotobacter and 50\% chemical fertilizer NDVI was 0.78 and no significant different was observed. Minimum NDVI (0.61) was observed in deficient Irrigation and without chemical and bio fertilizer. In both irrigation treatments with increasing of chemical and bio fertilizer 0.61 was increased (Table 3). On the other hand deficient irrigation decreased leaf NDVI from 0.76 to 0.68 .

The NDVI was developed to assess plant greenness and The Chllorophyll in leaves is responsible for the variability in greenness within a canopy. Data obtained from greenseeker, can be used for estimate yield prediction, biomass accumulation and growth rate, ground cover and early vigor, senescence pattern estimates, and for biotic and abiotic stress detection. NDVI technology is also used for making decisions in precision agriculture such as rate and timing of nitrogenous fertilizer applications (Pask et al., 2012). The NDVI has been correlated to many variables such as crop nutrient deficiency and long-term water stress and relationship between leaf $\mathrm{N}$ and leaf chlorophyll has been demonstrated for maize (Verhulst and Govaerts, 2010 A).

Results obtained in this experiment indicated that RWC decreased from $80.4 \%$ to $66.9 \%$ by deficient irrigation. Moreover vermicompost and chemical fertilizers had a significant effect on RWC (Table 4). Vermicompost and Azotobacter increased RWC, also by increasing the amount of chemical fertilizer, RWC increased. The maximum of RWC (81\%) was recorded in the plots where applied 6 ton/ha vermicompost and Azotobacter and chemical fertilizer but there was no significant difference between 0,50 and 100 percent of chemical fertilizers. The largest increased in Leaf relative water content due to the use of vermicompost. Whereas without chemical fertilizer and with use of 6 ton/ha vermicompost and Azotobacter, RWC was $80.6 \%$ and $69.4 \%$ in normal and Deficient Irrigation condition respectively.

Jabasingh \&t Saravana Babu (2014) had similar results and reported that the relative water content in leaves of different maize cultivars decreased significantly and with drought stress, the membrane permeability of the leaf cell markedly increased. Also Higher RWC indicates better growth and development, which in turn depends on leaf area (Sivakumar, 2014).

The yield of maize was significantly influenced by deficient irrigation; Results showed that grain yield was decreased from 8.2 ton/ha to 4.4 ton/ha by deficient irrigation. Water deficit in maize is one of limiting factors of yield and at the time of pollination, drought may

\begin{tabular}{|l|l|l|l|l|l|l|l|l|}
\hline Table 3: Effects of Chemical and bio fertilizer on NDVI \\
\hline & \multicolumn{3}{|c|}{ Deficient Irrigation } & \multicolumn{5}{c|}{ Normal Irrigation } \\
\hline Vermicompost (ton/ha) & 0 & 2 & 4 & 6 & 0 & 2 & 4 & 6 \\
\hline & & & & & & & & \\
\hline & & & & & & & & \\
\hline Chemical Fertilizers & & & & & & & & \\
\hline No Fertilizer & 0.61 & 0.63 & 0.65 & 0.66 & 0.69 & 0.73 & 0.75 & 0.75 \\
\hline $100 \%$ Recommendation & 0.68 & 0.69 & 0.69 & 0.71 & 0.77 & 0.77 & 0.77 & 0.78 \\
\hline
\end{tabular}


Table 4: Effects of Chemical and bio fertilizer on RWC

\begin{tabular}{|c|c|c|c|c|c|c|c|c|}
\hline & \multicolumn{4}{|c|}{ Deficient Irrigation } & \multicolumn{4}{|c|}{ Normal Irrigation } \\
\hline Vermicompost (ton/ha) & 0 & 2 & 4 & 6 & 0 & 2 & 4 & 6 \\
\hline No Fertilizer & 61.3 & 64.4 & 65.3 & 69.4 & 79.7 & 80 & 806 & 8 \\
\hline 50\% Recommendation & 62.8 & 65.3 & 65.3 & 69.8 & 80 & 80 & 80.6 & 80.7 \\
\hline 100\% Recommendation & 62.8 & 66.7 & 66 & 70 & 80 & 80 & 80.8 & 81 \\
\hline
\end{tabular}

have severe impact on yield. These results are consistent with previous work; Dagdelen et al. (2006) reported that water deficiency significantly affected maize yield and the highest maize yield was obtained from the full irrigation treatments. Stone et al. (2001) reported that water deficit reduces crop growth and morphological characteristics of maize plant. Pandey et al. (2000) reported that yield reduction $(22.6-26.4 \%)$ was found with deficit irrigation and this was associated with decrease in kernel number and weight.

Analysis of variance showed that Azotobacter increased grain yield about $89 \mathrm{~kg} / \mathrm{ha}$ in all treatments (Table 5). In addition the use of vermicompost at 2, 4 and 6 ton/ha consistently and significantly increased grain yield in normal and deficit irrigation (Table 5). Although, application of vermicompost led to increase in grain yield, the highest grain yield was related to integrated treatments 6 ton/h vermicompost and 100\% chemical fertilizers recommendation based on soil test. Results also indicated that the use of 6 ton/ha vermicompost and Azotobacter in soil, $50 \%$ of the maize fertilizer supplied.

The results showed that combined use of bio-fertilizers with chemical fertilizers increased the grain yield. Therefore the uses of biological fertilizers significantly reduce the consumption of chemical fertilizers and reduce the adverse environmental effects. On the other hand from this experiment, application of vermicompost in combination with chemical fertilizers showed better performance than only chemical fertilizers, even in 100\% recommendation based on soil test treatments. It can be stated that the increase in growth parameters of maize are due to greater availability of nitrogen in full organic and integrated treatments. In full chemical treatments most of nitrogen would be leached from the soil profile. In addition, high porosity and water holding capacity of vermicompost that helps in better aeration and drainage. Moreover use of 6 ton/ha vermicompost and Azotobacter in treatments with no chemical fertilizers produced 7 and 4.4 ton/ha grain yield in normal and deficit irrigation respectively. Application of organic manures either alone or integrated with chemical amendments for maize, performed better than all amendments tested in laboratory trails studied by Mujeeb et al. (2010).

Recommendations of organic matter alone with synthetic fertilizers could be helpful for enhancing stagnant wheat grain yield which have been reported by Tahir et al. (2011). Similarly Kemal and Abera (2015) reported application of recommended dose of inorganic fertilizer along with vermicompost at 6 ton/ha to maize not only enhanced productivity of maize but also improved soil fertility in terms of higher available N, P, K and organic carbon content over the control and recommended $\mathrm{N}, \mathrm{P}$ and $\mathrm{K}$.

\section{CONCLUSION}

Results obtained in this experiment indicated that, although the vermicompost and Azotobacter were not

\begin{tabular}{|l|l|l|l|l|l|l|l|l|l|}
\hline \multicolumn{2}{|l|}{ Table 5: Effects of Chemical and bio fertilizer on yield } \\
\hline
\end{tabular}


able to provide all the nutritional requirements for maize, but the results showed that combined use of biofertilizers with chemical fertilizers increased the evaluated characters. Hence the use of biological fertilizers also significantly reduce the consumption of chemical fertilizers and reduce the adverse environmental effects however, a good performance can be achieved in maize. On the other hand, the results showed that under deficient irrigation vermicompost and Azotobacter increased grain yield. As a general conclusion these results suggest that integrating organic sources with $50 \%$ of recommended NPK fertilizers are appropriate for sustainable crop production in normal and deficient irrigation. Similary Vanlawe et al (2002) reported that the conjunctive application of organics with inorganic sources of nutrients reduces the dependence on chemical inputs.

\section{ACKNOWLEDGMENT}

This work was supported by Agricultural and Natural Resources Research And Education Centre, Kermanshah, Iran

\section{REFERENCES}

Adhikary, S, 2012. Vermicompost, the story of organic gold: A review. Vol.3, No.7, 905-917. http://dx.doi.org/10.4236/ as.2012.37110

Akbari P, Ghalavand A, Modarres Sanavi S , 2009. Effects of Different Nutrition Systems (Organic, Chemical and Integrated) and Biofertilizer on Yield and Other Growth Traits of Sunflower (Helianthus annuus L.). Electronically J of Sustainable Agric. 19: 84-93. (Abstract in English)

Athar, H.R. and M. Ashraf, 2005. Photosynthesis under drought stress. In: Pessarakli, M. (ed.), Handbook of Photosynthesis, pp: 793-804. Taylor and Francis, New York

Cameron, R., Harrison-Murray, R. and Scott M, 1999. The use of controlled water stress to manipulate growth of containergrown. Sci. Biotechnol. 74, 161- 169.

Chamle D, Mogle U and Jadhav B. Effect of vermicoposts on chlorophyll content, leaf area and yield of maize, 2006. Geobios.33: 334-336.

Ciganda, V., Anatoly Gitelson, A. Schepers, J, 2008. Vertical Profi le and Temporal Variation of Chlorophyll in Maize Canopy: Quantitative Crop Vigor Indicator by Means of Refl ectance-Based Techniques. Agron. J. 100:1409-1417. Doi:10.2134/agronj2007.0322

Casa, R, 2003. Multiangular remote sensing of crop canopy structure for plant stress monitoring. PhD thesis. University of Dundee. www.unitus.it/.../dpv/R.Casa-PhD\%20Thesis,2003.pdf

Cvijanovic, G., Jonel, S, Dozet G , 2008. The significance of nitrogen-fixer as a biofertilizer in organic production. International Symposium on New Researches in Biotechnology, Ministry of Education and Research, University of Agronomical Sci- ences and Veterinary Medicine Bucharest. Special Volume, Serie F, Bucharest, November 20-21, ISSN 1224-7774. 574-582.

Dagdelen, N., E. Yılmaz, F. Sezgin and T. Gurbuz, 2006. Wateryield relation and water use efficiency ofcotton and second crop Maize in western Turkey. Agric. Water Management 82(12): 63-85.

Duhan, B.S., and Mahendera Singh, 2002. Effect of green manuring and nitrogen on yield and uptake of micronutrients of rice. J. Indian Soc. Soil. Sci., 50 (2): 178-180.

Earl, H and Richard F. Davis, 2003. Effect of Drought Stress on Leaf and Whole Canopy Radiation Use Efficiency and Yield of Maize. Agron. J. 95:688-696.

Efeoglu, B., Ekmekci Y., Cicek N, 2009. Physiological responses of three maize cultivars to drought stress and recovery. S Afr J Bot. 75:34-42.

Eidi zadeh. Kh, Mahdavi damghani, A., Sabahi, H., Soofizadeh, S, 2010. Effects of application of biological fertilizers in corporation of chemical fertilizers on growth of Shooshtar Zea mays cultivar. J of Agro. 2: 292-301. (Abstract in English)

Govaerts, B., and Verhulst, N, 2010. The normalized difference vegetation index (NDVI) GreenSeekerTM handheld sensor: Toward the integrated evaluation of crop management. Part A: Concepts and case studies. Mexico, D.F.; CIMMYT.

Janos, N, 2010. Impact of fertilization and irrigation on the correlation between the soil plant analysis development value and yield of maize. Commun.Soil Sci. Plant Anal., 41: 12931305. DOI: $10.1080 / 00103621003759304$

Jones, C.L., Weckler, P. R., Maness, N.O., Jayasekara, R. Stone, M.L. and D. Chrz, 2007. Remote sensing to estimate chlorophyll concentration in spinach using multi-spectral plant reflectance. Transactions of ASAE 50(6): 2267-2273

Jonckheere, I., Fleck, S., Nackaerts, K., Muys, B., Coppin, P., Weiss, M. and F. Baret, 2004. Review of methods for in situ leaf area index determination Part I. Theories, sensors and hemispherical photography. Agricultural and Forest Meteorology, 121 (1): 19-35.

Kemal, Y.O. and Merkuz Abera, 2015.Contribution of integrayed nutrient management practice for sustainable crop productivity, nutrient uptake and soil nutrient status in Maize based cropping systems. Journal of Nutrients, 2015, 2(1):1-10. http://www.pakinsight.com/?ic=journalEtjournal=87

Lelei, JJ., Onwonga, RN., Freyer, B, 2009. Organic based nutrient management strategies: Effect on soil nutrient availability and maize (Zea mays L.) performance in Njoro, Kenya. Afr. J. Agric. Res., 4: 092-099.

Leon, C.T., D.R. Shaw, M.S. Cox, M.J. Abshire, B. Ward and M.C. Wardlaw, 2003. Utility of remote sensing in predicting crop and soil characteristics. Precision Agriculture 4: 359-384.

Li, WJ., Ni, YZ, 1996. Researches on application of microbial inoculant in crop production. In: Researches and application of En technology, Agriculture University Press, Beijing, China, pp: $42-84$

Manyuchi, MM., Kadzungura, L., Phiri, A. and Muredzi P, 2013. Effect of vermicompost, vermiwash and application time on 
Zea mays Growth. International Journal of Scientific Engineering and Technology 2(7) 638-641.

Mujeeb, F., Rahmatullah, J., Akhtar and Ahmad, R, 2010. Integration of organic and inorganic P sources for improving $\mathrm{P}$ use efficiency in different soils. Soil and Environment, 29:122-127.

Munne-Bosch, S. and Alegre, L, 2000. Changes in carotenoids, tocopherols and diterpenes during drought and recovery, and the biological significance of chlorophyll loss in Rosmarinus officinalis plants. Planta 210, 925-931.

Muscolo, A., Sidari, M., Attina, E., Francioso, 0., Tugnoli, V., Nardi, S, 2007. Biological activity of humic substances is related to their chemical structure, Soil Sci. Soc. Am. J. 71: 75-85.

NAS, 2003.Frontiers in Agricultural Research: Food, Health, Environment, and Communities. Washington D.C., National Academy of Sciences.

O’Neill, P.M., Shanahan, J.F. and J.S. Schepers, 2004. Agronomic Responses of Corn Hybrids from Different Eras to Deficit and Adequate Levels of Water and Nitrogen. Agron. J. 96:1660-1667

Pandey, R.K., J.W. Maranville and M.M. Chetima, 2000. Deficit irrigation and nitrogen effects on maize in a Sahelian environment: II. Shoot growth, nitrogen uptake and water extraction. Agric. Water Manage., 46: 15-27. DOI: 10.1016/s03783774(00)00074-3

Pandurang,M.2014. Efficacy of weed vermicompost and chemical fertilizer on yield, morpho-physiological and biochemical investigations of Maize. Int. Res. J. of Science \& Engineering,Vol. 2(1):19-22

Paroda,R., Prasanna, B.M. Bhag Mal, Dasgupta, S. and Jat, M.L. 2014. 12th Asian Maize Conference and Expert Consultation on Maize for Food, Feed, Nutrition and Environmental Security. Bangkok, Thailand. 30 October - 1 November, 2014.

Pask, AJD., Pietragalla, J., Mullan, DM. and Reynolds, MP.2012. Physiological Breeding II: A Field Guide to Wheat Phenotyping. Mexico, D.F.: CIMMYT.

Peterson, T.A., Blackmer, T.M.; Francis, D.D., Schepers, J.S, 1993. Using a Chlorophyll Meter to Improve N Management. Nebguide G93-1171A. Coop. Ext. Serv., Univ. of Nebraska, Lincoln.

Potter, E., J. Wood, and C. Nicholl, 1996. SunScan canopy analysis system: Users manual. Delta-T Devices, Cambridge, UK.

Rambo, L., B.L. Ma, Y. Xiong and P.R.F. da Silvia, 2010. Leaf and canopy optical characteristics as crop-N-status indicators for field nitrogen management in corn. J. Plant Nutr. Soil Sci., 173: 434-443. DOI: 10.1002/jpln.200900022

Rasheeed, M., Hussain, A., Mahmood, T, 2003. Growth analysis of hybrid maize as influenced by planting techniques and nutrient management. International J of Agric \&t biolo. 5:169-171.

Reicosky, D.C, 2005. Alternatives to mitigate the greenhouse effect: emission control by carbon sequestration. In: Simposio sobre Plantio direto e Meio ambiente; Seqüestro de carbono equalidade da agua, pp. 20-28.. Anais. Foz do Iguaçu, 18-20 de Maio 2005.
Saini, VK., Bhandari, SC., Tarafdar, JC, 2004. Comparison of crop yield, soil microbial C.N. and P, N-fixation, nodulation and mycorrhizal infection in inoculated and non-inoculated sorghum and chickpea crops. Field Crops Res. 89: 39-47.

Santosh, M., Swapnil Deshmukh, Prashant Shinde and Vishal Deshmukh, 2013. Effect of integrated nitrogen management with vermiwash in corn (Zea mays L.) on growth and yield African Journal of Agricultural Research Vol. 8(38), pp. 47614765. DOI:10.5897/AJAR2013.7304

Sharma, K., Dak G., Agrawal A., Bhatnagar M. and Sharma R, 2007. Effect of phosphate solubilizing bacteria on the germination of Cicer arietinum seeds and seedling growth. Journal of Herbal Medicine and Toxicology, 1(1):61-63

Sivakumar, R, 2014. Effect of drought on plant water status, gas exchange and yield parameters in Contrasting genotypes of Tomato (Solanum lycopersicum). American International Journal of Research in Formal, Applied \&t Natural Sciences, 8(1), pp. 57-62.

Stone, P.J., Wilson, D.R., Jamieson, P.D. and R.N. Gillespie, 2001. Water deficit effects on sweet Maize. II. Canopy development. Aust.J.Agric. Res. 52: 115-126.

Sujatha, MG., Lingraju, BS., Palled, YB., Ashalatha, KV, 2008. Importance of Integrated Nutrient Management Practices in Maize under Rainfed Condition. Karnataka J. Agric. Sci., 21: 334-338.

Tahir, M., Ayub, M., Javeed, H.M.R., Naeem, M., Rehman, H., Waseem, M. and Ali, M, 2011. Effect of different organic matter on growth ad yield of wheat (Triticum aestivum L). Pakistan Journal of life and Social Sciences, 9: 63-66.

Tripathi, S., Joshi, HC., Sharma, DK., Singh, JP, 2007. Response of wheat and corn to biocompost prepared from distillery effluent and pressmud. Indian J. Agric. Sci. 77(4):208-211.

Vanlawe, B., Diets, J., Sanginga, N. and Merckx, R, 2002. Integrated plant nutrient management in Sub-Saharan Africa: From Concept to practice. Nallingford, U.K: CABI Publishing.

Verhulst, N., Govaerts, B, 2010. The normalized difference vegetation index (NDVI) GreenSeekerTM handheld sensor: Toward the integrated evaluation of crop management. Part A: Concepts and case studies. Mexico, D.F.; CIMMYT.

Verma, N.K, 2011. Integrated nutrient management in winter maize (Zea mays L.) sown at different dates. Journal of Plant Breeding and Crop Science Vol. 3(8), pp. 161-167.

Vetsch, J.A. and G.W. Randall , 2004. Corn production as affected by nitrogen application timing and tillage. Agron. J., 96: 502-509. DOI:10.2134/agronj2004.5020

Yadav, RD., Keshwa, GL., Yadva, SS, 2002. Effect of integrated use of FYM, urea and sulphur on growth and yield of Isabgol (Plantago ovata). J Medicinal and Aromatic Plant Sci. 25: 668671.

Yu, Huan., Huasong, Wu. and Wang Zhijie, 2010. Evaluation of SPAD and Dualex for in-season corn nitrogen status estimation. Acta Agronomica Sinica 36: 840-847. 